\title{
Zinc oxide nanorod based immunosensing platform for the determination of human leukemic cells
}

\author{
Alexander Tamashevski ${ }^{\mathrm{a}, *}$, Yuliya Harmaza ${ }^{\mathrm{a}}$, Roman Viter $^{\mathrm{b}, \mathrm{e}, *}$, Daniels Jevdokimovs ${ }^{\mathrm{c}}$, \\ Raimond Poplausks ${ }^{\mathrm{c}}$, Ekaterina Slobozhanina ${ }^{\mathrm{a}}$, Lina Mikoliunaite ${ }^{\mathrm{d}}$, Donats Erts ${ }^{\mathrm{c}}$, \\ Almira Ramanaviciene ${ }^{\mathrm{f}}$, Arunas Ramanavicius ${ }^{\mathrm{d}, *}$ \\ ${ }^{a}$ Institute of Biophysics and Cell Engineering of National Academy of Sciences of Belarus, Akademicheskaya St. 27, Minsk 220072, Belarus \\ ${ }^{\mathrm{b}}$ Institute of Atomic Physics and Spectroscopy, University of Latvia, 19, Raina Blvd, 1586 Riga, Latvia \\ ${ }^{\mathrm{c}}$ Institute of Chemical Physics, University of Latvia, 19, Raina Blvd, 1586 Riga, Latvia \\ ${ }^{\mathrm{d}}$ Department of Physical Chemistry, Faculty of Chemistry, Vilnius University, Naugarduko 24, LT-03225 Vilnius, Lithuania \\ ${ }^{\mathrm{e}}$ Medical Institute, Sumy State University, 31, Sanatornaya st., 40018 Sumy, Ukraine \\ ${ }^{\mathrm{f}}$ NanoTechnas - Centre of Nanotechnology and Materials Science, Faculty of Chemistry and Geosciences, Vilnius University, Naugarduko 24, LT-03225 Vilnius, Lithuania
}

\section{A R T I C L E I N F O}

\section{Keywords:}

ZnO-nanorods

Human lymphocytes

B-lymphoblast cells

Monoclonal antibody

Flow cytometry

Photoluminescence

\begin{abstract}
A B S T R A C T
Zinc oxide $(\mathrm{ZnO})$ based nanostructures owing unique physical properties - high photoluminescence, biocompatibility and other characteristics, therefore, they attract attention as building blocks suitable for biosensor development. In this research as a target we have used human leukemic cell line IM9 (IM9). IM9 was derived from the patient with a multiple myeloma and expressed cluster of differentiation proteins CD19 on the surface of $85-95 \%$ here investigated cancer cells. As a control sample healthy human's peripheral blood mononuclear cells (PBMC) were used and the expression of CD19 protein was found only in 5-9\% of these cells. Two types of antibodies labeled by fluorescein isothiocyanate (FITC) were used for the labeling of human leukemic cells: FITC-conjugated mouse antibodies against Human CD19 protein (anti-CD19-FITC*) and FITC-conjugated mouse antibodies against Human IgG1 protein (anti-IgG1-FITC*). In order to demonstrate the applicability of zinc oxide nanorods (ZnO-NRs) based platforms three types of ZnO-NRs-based structures were investigated: (i) ZnO-NRs modified by anti-CD19-FITC*; (ii) ZnO-NRs modified by IM9 cells, which were pre-incubated with anti-CD19FITC*; (iii) ZnO-NRs modified by PBMC cells, which were pre-incubated with anti-CD19-FITC*. It was demonstrated that IM9 cells after specific interaction with anti-CD19-FITC* bind to ZnO-NRs (ZnO-NRs/ IM9 + anti-CD19-FITC*) and photoluminescence based signal significantly increase in comparison with that observed in control samples, which contained PBMC cells incubated with anti-CD19-FITC* (ZnO-NRs/ PBMC + anti-CD19-FITC ${ }^{*}$. The photoluminescence results are in good correlation with the data obtained by flow cytometry. This study illustrate that $\mathrm{ZnO}-\mathrm{NRs}$ exhibit a photoluminescence signal suitable for the determination of anti-CD19-FITC* labeled IM9 cell line at concentrations - from 10 till 500 cells adsorbed per $1 \mathrm{~mm}^{2}$ of $\mathrm{ZnO}$ NRs platform.
\end{abstract}

\section{Introduction}

Chronic lymphocytic leukemia (CLL) is a human monoclonal disorder characterized by a progressive accumulation of functionally incompetent lymphocytes (B cells). The leukemia cells are produced in the bone marrow but then go into the blood. In time, the cells can spread to other parts of the body, including the lymph nodes, liver, and spleen $[1,2]$. With more than 15,000 cases recognized annually, CLL is the most common form of leukemia diagnosed in adults in Western countries, resulting in almost 5000 cancer-related deaths yearly in the
United States [3]. In CLL, the leukemia cells often build up slowly over time, and many people don't have any symptoms for at least a few years [2]. Despite the fact that the modern approaches of therapy prolong the remission in CLL patients, to date, this disease is considered an incurable one [4].

Nowadays, the diagnosis of this disease includes: 1) analysis of the B-cells amount in human peripheral blood, 2) analysis of blood smears for determination of tumor cells morphology, 3) cytogenetic analysis to detect the presence of the specific DNA sequences on chromosomes, 4) bone marrow aspiration and biopsy and 5) the peripheral lymphocytes

\footnotetext{
* Corresponding authors.

E-mail addresses: tayzoe@gmail.com (A. Tamashevski), roman.viter@lu.lv (R. Viter), Arunas.Ramanavicius@chf.vu.lt (A. Ramanavicius).
} 
immunophenotyping [2,3]. Lymphocytes immunophenotyping using flow cytometry is mandatory for the confirmation of diagnosis. Such a high-sensitivity method as flow cytometry can detect one cancer cell in the presence of 10,000 normal leukocytes [5]. Hence, recently very actual task is to develop a new, simple leukemia diagnostic tool of their use compared to flow cytometry. A suitable solution of here posed problem can be a device based on biosensor technology [6], in particular immunosensors $[7,8]$. The advantages of the immunosensors are simple instrumentation, high sensitivity and selectivity, and compatibility with miniaturized and portable systems [9].

Zinc oxide $(\mathrm{ZnO})$ is an important wide band gap semiconductor material having a great potential of application in catalysis, sensing and nano-device development based on its unique physical properties. Nanostructured ZnO not only possesses high surface area, good biocompatibility and chemical stability being non-toxic, but it also shows biomimetic and high electron communication features important for potential applications in biosensing [6]. The surface of $\mathrm{ZnO}$ nanomaterials has chemical functionality required for covalent derivatization to allow linking of specific biomolecules and to increase specificity of biomolecular interaction [10].

However, the application of $\mathrm{ZnO}$ in biological or clinical testing schemes have remained largely unexplored, so far even though many biological assay systems rely on optical detection techniques. Photoluminescence is one of the most widely used detection mechanisms in many fields such as biology, biophysics, biochemistry, genomics, proteomics, drug discovery, disease diagnostics and environmental analysis. Major challenges associated with such fluorescence techniques include enhancing detection sensitivity and increasing signal-to-noise ratio. Novel methods that overcome current drawbacks and enable rapid, facile, high-throughput, ultrasensitive, and specific optical detection are in great demand [6].

Many efforts have been recently made to construct ZnO-based biosensors with high performance [11,12]. Corso et al. [13] developed an effective antibody immobilization technique that imparts sensitivity and specificity to the ZnO-based devices. Moreover, using ZnO-based quantum dots as electrochemical and fluorescent labels, a sandwich type sensitive immunoassay was developed to detect carbohydrate antigen 19-9, which is a preferred label for pancreatic [14]. Viter et al. have previously developed system for the detection of Salmonella and Ochratoxin A by ZnO-nanorods based photoluminescence system $[15,16]$. It was found that the immobilization of bioselective layers, which are based on anti-Salmonella or anti-Ochratoxin $A$ antibodies, immobilized onto ZnO-nanorods lead to an increase of the intensity of photoluminescence and after interaction with Salmonella and Ochratoxin $A$ antigens the intensity of PL is decreasing proportionally to antigens concentration.

Previously we also have reported on a portable analytic system for cancer cell detection [17]. In this work colloidal solution of ZnO-nanorods were used for the visualization of target cancer cells (adherent carcinoma cells) attached to a glass slide surface.

In the present work we have demonstrated applicability of $\mathrm{ZnO}$ nanorod-based layer for the development of immunosensing platform suitable for the detection cancer (B-lymphoblastoid cell line IM9) cells.

\section{Materials and methods}

\subsection{Materials}

Blood from healthy donors was obtained from the Republic Research \& Production Center for Transfusiology and Medical Biotechnologies (Minsk, Belarus). Cell line IM9 (ATCC CCL 159) was obtained from Institute of cytology of RAN (St. Petersburg, Russia).

All the chemicals in the experiment were used without further purification. Histopaque-1077, trypan blue, RPMI-1640 medium, fetal bovine serum, L-glutamine, penicillin, streptomycin, L-butanol, ethanol, paraformaldehyde were purchased from (Sigma-Aldrich,
Germany). Fluorescein isothiocyanate (FITC)-conjugated mouse against human CD19 (anti-CD19-FITC*) monoclonal antibody (Mab), FITC*conjugated mouse against Human IgG1 polyclonal antibody (anti-IgG1FITC*) were purchased from (Beckman Coulter, USA).

\subsection{Cells and cell culture}

PBMC cells were isolated from heparinized peripheral blood from healthy donors by centrifugation on a Histopaque density gradient (density: $1.077 \mathrm{~g} / \mathrm{ml}$ ), washed twice in $10 \mathrm{mM}$ Phosphate buffer saline $\mathrm{pH} 7.2$ (PBS) at $300 \times \mathrm{g}$ for $30 \mathrm{~min}$ and re-suspended in culture medium (RPMI-1640 with $10 \%$ FBS) at a final density of $1 \times 10^{6}$ cells $/ \mathrm{ml}$. Cell viability was determined by Trypan blue dye exclusion. The purified PBMC were used for experimental analysis within 1 day from their isolation.

Human lymphoblastoid cell line IM9 (IM9) was cultured in a complete RPMI-1640 medium supplemented with $10 \%(\mathrm{v} / \mathrm{v})$ heat-inactivated fetal bovine serum (FBS) $\left(56^{\circ} \mathrm{C}\right.$ for $60 \mathrm{~min}$ ), L-glutamine ( $2 \mathrm{mmol} / \mathrm{L})$, penicillin $(100 \mathrm{U} / \mathrm{ml})$, streptomycin $(100 \mu \mathrm{g} / \mathrm{ml})$ at $37^{\circ} \mathrm{C}$ in a $5 \% \mathrm{CO}_{2}: 95 \%$ air humidified atmosphere. Only exponentially growing cultures of cells were used in the experiments.

\subsection{Flow cytometry analysis of cells surface marker}

IM9 and PBMC cells were analyzed for B-cell subpopulations by flow cytometry. Cell suspensions $\left(1 \times 10^{6}\right.$ cells $\left./ \mathrm{ml}\right)$ were stained for surface marker expression using anti-CD19-FITC* and anti-IgG1-FITC** for $1 \mathrm{~h}$ at room temperature in a dark and twice washed with PBS $300 \times g$ for $10 \mathrm{~min}$. Cells were analyzed using FACSCanto II BD Biosciences (BD Biosciences, San Jose, USA). For analysis, forward and side scatter gates were set to include viable cells and to exclude dead cells and debris. A minimum of 20000 lymphocyte-gated events was acquired on a flow cytometry, with data analyzed by FCSExpress Version 3 Research Edition De Novo software for enhanced acquisition analysis from De Novo (Glendale, USA).

\subsection{The synthesis of ZnO-nanorods}

ZnO-nanorods (ZnO-NRs) were obtained by the gaseous-disperse synthesis (GDS) [18]. The method comprises specially organized twophase flames of dust clouds of the corresponding metals (pure metals, mechanical mixtures or alloys of different metals). The final product is obtained as a result of condensation of gaseous phase products of metal burning in the oxidizing atmosphere. For further use of ZnO-NRs, they were dispersed in 99,8\% 1-butanol in order to prepare $10 \mathrm{mg} / \mathrm{ml} \mathrm{al-}$ cohol solution and then ultrasonically treated for $30 \mathrm{~min}, 44 \mathrm{kHz}$.

\subsection{The preparation of ZnO-nanorod-based platform}

$18 \mathrm{~mm}$ square glass cover slips and $1-10 \mathrm{mg} / \mathrm{ml}$ zinc oxide nanorods stock solutions were used for the preparation of platforms. Glass substrate was cleaned in $70 \%$ ethanol and deionized water and treated oxygen plasma using Plasma Cleaner from Harrick Plasma (Ithaca, USA). After that $10 \mu \mathrm{l}$ of ZnO-NRs stock solution was dropped on glass substrate and dried at room temperature for $12 \mathrm{~h}$. The $\mathrm{ZnO}-\mathrm{NRs}$ formed a layer on the substrate (glass/ZnO-NRs), which was further annealed at $300^{\circ} \mathrm{C}$ in air atmosphere for $2 \mathrm{~h}$. In this way glass/ZnO-NRs platform was prepared for the modification by FITC $*$-labeled antibodies and cells.

\subsection{Modification of glass/ZnO-NRs by antibodies and antibody-pre-treated} cells

Three types of ZnO-NRs-based samples were prepared for investigations: 
1) Anti-CD19-FITC* and anti-IgG1-FITC* antibodies were adsorbed on the glass/ZnO-NRs substrate in order to form glass/ZnO-NRs/antiCD19-FITC* structures and glass/ZnO-NRs/anti-IgG1-FITC* structures. For this $4 \mu \mathrm{l}$ of anti-CD19-FITC* and anti-IgG1FITC* (final concentration was $1.25-25.0 \mu \mathrm{g} / \mathrm{ml}$ ) was dropped on $\mathrm{ZnO}$ nanorod modified substrates and maintained for $12 \mathrm{~h}$ at $4{ }^{\circ} \mathrm{C}$. Then antibodies were fixed by $1 \%$ solution of paraformaldehyde in PBS, pH 7.2.

2) Human leukemia cells (IM9) were incubated with anti-CD19FITC* or anti-IgG1-FITC* antibody ( $1 \mathrm{~h}$ at room temperature) and then the solution of FITC* modified IM9 cells (IM9 + anti-CD19FITC* and IM9+anti-IgG1-FITC*, respectively) was deposited on the glass/ZnO-NRs substrates and incubated for $12 \mathrm{~h}$ at $4{ }^{\circ} \mathrm{C}$ in order to form glass/ZnO-NRs/IM9 + anti-CD19-FITC* or glass/ZnO-NRs/ IM9 + anti-IgG1-FITC* structures, respectively. These samples were washed with PBS, $\mathrm{pH}$ 7.2, in order to remove unbounded IM9 and IM9 + anti-IgG1-FITC* or IM9 + anti-IgG1-FITC*cells from glass/ ZnO-NRs surface. After this cells were fixed by $4 \%$ solution of paraformaldehyde in PBS pH 7.2.

3) The same procedures were performed with 'control' samples of healthy human's peripheral blood mononuclear cells (PBMC). PBMC cells were incubated with both types of antibodies (with anti-CD19FITC* or anti-IgG1-FITC* antibody) and then FITC* modified PBMC cells (PBMC + anti-CD19-FITC* and PBMC + anti-IgG1-FITC*, respectively) was deposited on the glass/ZnO-NRs substrates and incubated for $12 \mathrm{~h}$ at $4{ }^{\circ} \mathrm{C}$ in order to form glass/ZnO-NRs/ PBMC + anti-CD19-FITC* or glass/ZnO-NRs/PBMC + anti-IgG1FITC* structures, respectively. These samples were washed with PBS, pH 7.2, in order to remove unbounded PBMC and PBMC + antiIgG1-FITC* or PBMC+anti-IgG1-FITC* cells from glass/ZnO-NRs surface. After this cells were fixed by $4 \%$ solution of paraformaldehyde in PBS pH 7.2.

Further characterization of structural and optical properties was performed for the next structures: glass/ZnO-NRs, glass/ZnO-NRs/antiCD19-FITC* , glass/ZnO-NRs/anti-IgG1-FITC* , glass/ZnO-NRs/ PBMC + anti-CD19-FITC* , glass/ZnO-NRs/IM9 + anti-CD19-FITC* and glass/ZnO-NRs/IM9 + anti-IgG1-FITC*.

\subsection{Imaging by scanning electron microscopy}

The morphology of the obtained samples (bare $\mathrm{ZnO}$ nanorods substrates as well as $\mathrm{ZnO}$ substrates modified with monoclonal antibody and cells) was studied by scanning electron microscopy (SEM). Cells were prepared for SEM imaging by fixation on the substrate with $4 \%$ PFA buffered in PBS pH 7.2. Scanning electron microscopy imaging was performed by electron microscope S-4800 FE-SEM from Hitachi (Krefeld, Germany). Images of samples were taken at $1.0-35.0 \mathrm{k} \times$ magnifications with acceleration voltages ranging $1.0-5.0 \mathrm{kV}$.

\subsection{Photoluminescence analysis of $\mathrm{ZnO}-\mathrm{NRs}$ based structures}

Photoluminescence (PL) spectra of glass/ZnO-NRs-based structures at room temperature were registered and they were similar to that reported by Viter et al. $[7,15,19,20]$. PL was excited using UV solid state laser LGI-21 (output power $0.4 \mathrm{~mW}$, with $337 \mathrm{~nm}$ excitation wavelength). The emission spectra were recorded at room temperature in the range of $370-800 \mathrm{~nm}$ using spectrometer HR2000 + (Ocean Optics).

\subsection{Raman microscopy analysis}

The bare glass/ZnO-NRs as well as glass/ZnO-NRs/anti-CD19-FITC* and that structures treated by target-cells (glass/ZnO-NRs/IM9+ antiCD19-FITC*) were investigated using Raman spectroscopy (RS). Raman spectroscopy experiments were performed using combined Raman and SNOM microscope Alpha 300 RS (WiTec, Germany), equipped with
$532 \mathrm{~nm}$ excitation laser source. Laser light filtered by a plasma filter was focused onto the sample with 100x objective. The scattered Raman signal was collected with the same objective in the backscattering geometry and detected by CCD detector cooled down to $-61^{\circ} \mathrm{C}$.

\section{Results and discussion}

\subsection{Microstructure and photoluminescence properties of bare $\mathrm{ZnO}$ nanorods}

Analysis of the literature showed that ZnO-NRs have attracted attention for biosensing applications due to their chemical stability, high specific surface area, and electrochemical activity $[6,21,22]$. Based on the evidence that the use of ZnO-NRs-based platforms may facilitate a sensitive fluorescence detection of biomolecules [23], the ZnO-NRsbased platforms have been evaluated for enhanced fluorescence assays involving component of biological systems such as DNA and proteins $[23,24]$. In more complex biological assays of multi-component systems, ZnO-NRs-based platforms have demonstrated their impact on the sensitive fluorescence detection of cancer and kidney disease biomarkers [25]. Therefore, the first stage of our work was to create and to analyze/characterize ZnO-NRs-based platforms suitable for the application in immunosensors.

The microstructure of obtained ZnO-NRs deposited on a glass substrate was characterized by SEM. Fig. 1 displays typical SEM images of ZnO-NRs in a stripe array sample. ZnO-NRs prepared according to our method are uniform in diameter, length, and crystalline structure. The average diameter of the $\mathrm{ZnO}-\mathrm{NRs}$ was about $50 \mathrm{~nm}$ and the length of ZnO-NRs could reach up to $500 \mathrm{~nm}$.

The room temperature photoluminescence (RT-PL) spectrum of bare glass/ZnO-NRs substrate is shown in Fig. 2. The registered PL spectrum has two peaks: (i) a narrow and intense peak, which is centered at $380 \mathrm{~nm}$ and (ii) a wide non-symmetric peak, which is centered at $520 \mathrm{~nm}$. The photoluminescent properties of ZnO-based nanostructures usually exhibit near-band-edge (NBE) emissions and the broad deeplevel emission (DLE) or visible luminescence due to exciton transitions and defect emission, respectively [26].

The structural, optical and electrical properties of $\mathrm{ZnO}$ nanostructures are strongly interrelated [26,27]. Usually the NBE/DLE ratio of $\mathrm{ZnO}$ nanostructures increases with the optimization of composition stoichiometry [26]. However the light emission properties of $\mathrm{ZnO}$ nanostructures are affected by surface layer depletion in case of a high ratio of surface to volume [27]. The NBE and DLE intensities are reduced as photo-generated electrons are captured on surface increasing the band bending and excitons dissociate in the electrical field, induced by the surface charge $[15,26]$. Due to the expected sensing mechanism in present work we have focused on the NBE emission peak intensity, which in this particular case is the most informative analytical signal.

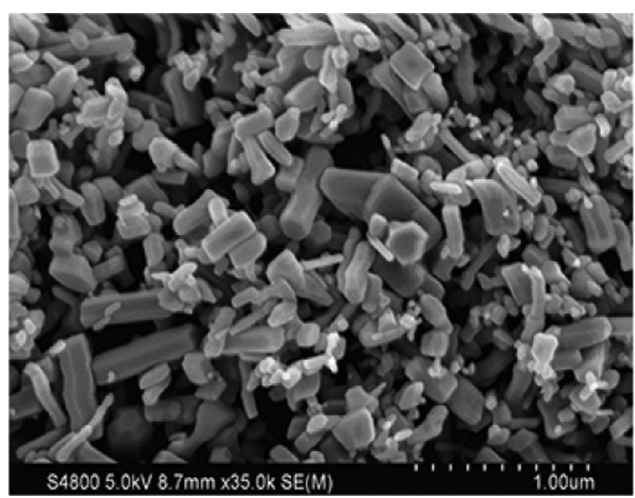

Fig. 1. SEM images of ZnO-NRs deposited on glass (glass/ZnO-NRs). 


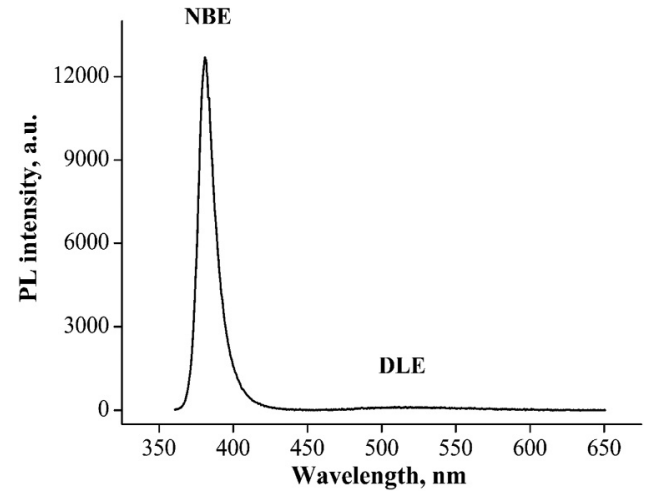

Fig. 2. Room temperature photoluminescence of bare glass/ZnO-NRs structure (excitation at $337 \mathrm{~nm}$ ). Two main emission peaks, near band edge (NBE) and deep-level (DLE) emissions, are marked in the spectrum with $\lambda=380 / 510 \mathrm{~nm}$ correspondingly.

Prior to the evaluation of glass/ZnO-NRs-based platforms the optimal ZnO-NRs concentration was determined. In order to achieve this goal the following ZnO-NRs concentrations were tested: $1 \mathrm{mg} / \mathrm{ml}$; $2.5 \mathrm{mg} / \mathrm{ml} ; 5 \mathrm{mg} / \mathrm{ml} ; 10 \mathrm{mg} / \mathrm{ml}$.

The NBE part of the PL spectra of ZnO-NRs, deposited on glass substrates from solutions with different concentrations is shown in Fig. 3. The PL intensity of ZnO-NRs non-significantly increases with an enhancement of the concentration of ZnO-NRs in solution. Also, no linear dependence between PL intensity and concentrations of ZnO-NRs in solution is observed. Moreover, the PL intensity of ZnO-NRs at concentrations of 5 and $10 \mathrm{mg} / \mathrm{ml}$ was almost the same, it indicate the achievement of a saturation of PL signal at ZnO-NRs concentrations, which are exceeding $5 \mathrm{mg} / \mathrm{ml}$.

SEM microstructure studies of obtained ZnO-NRs are shown in SEM images (Fig. 4) ZnO-NRs at concentration of $1 \mathrm{mg} / \mathrm{ml}$ formed a monolayer on glass substrate whereas when level of $\mathrm{ZnO}$-NRs was more than $1 \mathrm{mg} / \mathrm{ml}$ the deposited $\mathrm{ZnO}$-NRs overlapped and formed conglomerates. It indicates about the maximum degree of packing of $\mathrm{ZnO}-\mathrm{NRs}$ in current volume and surface area occupied by them after the annealing. Increase in PL intensity in the case of $2.5 \mathrm{mg} / \mathrm{ml} \mathrm{ZnO-NRs} \mathrm{compared}$ with $1 \mathrm{mg} / \mathrm{ml}$ indicates about the increase of ZnO-NRs packing degree in present surface area, however, this leads to the formation of not uniform layer. Thus, $1 \mathrm{mg} / \mathrm{ml} \mathrm{ZnO-NRs} \mathrm{deposited} \mathrm{on} \mathrm{a} \mathrm{glass} \mathrm{substrate} \mathrm{is}$ an optimal concentration for the further preparation of $\mathrm{ZnO}$-NRs-based platform.

\subsection{The determination of immuno-phenotype of donor's lymphocytes and} IM9 cell line by flow cytometry using anti-CD19-FITC*

As mentioned in the introduction part, B-CLL is a disease characterized by a pathologic accumulation of the immunologically

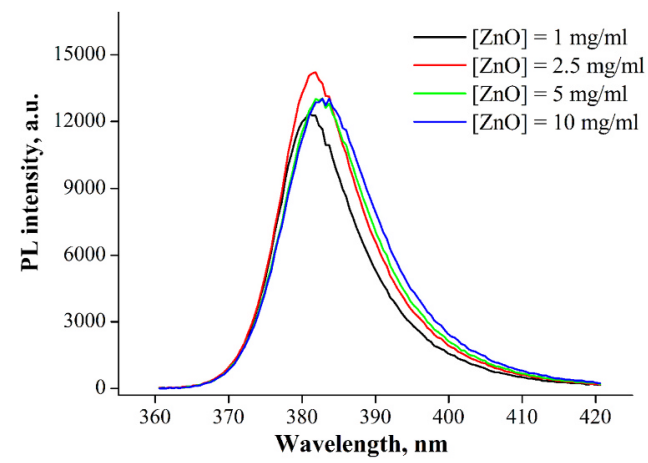

Fig. 3. Room temperature photoluminescence of bare ZnO-NRs in concentration interval of $1-10 \mathrm{mg} / \mathrm{ml}$. incompetent B-lymphocytes in the bone marrow, lymph nodes, liver, spleen and peripheral blood [1]. In normal peripheral blood, CD19 protein or B-lymphocytic antigen CD19 is expressed on the cell membrane at $5-20 \%$ of total lymphocytes population [1]. To investigate the expression of CD19 protein on B-leucosis lymphocytes, the human Blymphoblastoid cell line IM9 was studied, because it is known that this cell line has CD19 antigen expression.

Figs. 5 and 6 correspond to representative dot plots distribution profiles of donor's peripheral mononuclear cells and human B-lymphoblastoid cell line IM9 during the evaluation of CD19 marker expression on their surface. Figs. 5A and 6A show donor's lymphocytes and $B$ lymphoblast cells gates, respectively, sorted according to forward side scatter (FSC) and side scatter (SSC). Also the auto-fluorescence of targeted cells (Figs. 5B, 6B) and a sample of cells that has been stained with anti-CD19-FITC* (Figs. 5D and 6D) are represented. The overall positive expression rates of CD19 marker (CD19 positive cells) in donor's lymphocytes is $4.62 \%$ (Fig. 5D) and in human B-lymphoblastoid cell line IM9 is $95.02 \%$ (Fig. 6D).

It is known that antibodies can bind to cells in a specific manner, where the Fab (fragment antigen-binding) fragment of the antibody binds to a high-affinity specific target or the Fc (fragment crystallizable) fragment of the antibody binds to the Fc receptors on the surface of cells. However, they can also bind in a nonspecific manner, where the Fab fragment binds to a low affinity, non-specific target. Hence, in order to increase selectivity of cell determination, at the same time we have used isotype control for anti-CD19 monoclonal antibody. IgG1 in our case is a negative control designed to measure the level of nonspecific background signal caused by anti-CD19 monoclonal antibody, based upon the tissue type of the sample. This background signal is the result of non-specific immunoglobulin's binding to $\mathrm{Fc}$ receptors present on the B-cell surface. Figs. 5C and 6C show samples of investigated cells that have been labeled with anti-IgG1-FITC*. In this case the overall positive expression rates of IgG1 (a nonspecific binding) in donor's lymphocytes is $0.23 \%$ (Fig. 5C) and in the human B-lymphoblastoid cell line is $0.32 \%$ (Fig. 6C).

\subsection{The evaluation of photoluminescent properties of ZnO-nanorods after the adsorption of monoclonal antibodies}

Optical properties of glass/ZnO-NRs platforms after the modification with anti-CD19-FITC* monoclonal antibody (glass/ZnO-NRs/antiCD19-FITC*) in order to find conditions for further determination of photoluminescence-based analytical signal have been investigated. FITC conjugated anti-human CD19 monoclonal antibody (anti-CD19FITC*) were applied. It is known that FITC has emission bands in visible range from $480 \mathrm{~nm}$ to $640 \mathrm{~nm}$, but NBE part of ZnO-NRs spectrum does not exhibit emission in this spectrum range [15]. This enables to use the same monoclonal antibody (anti-CD19-FITC*) for an immunophenotypic analysis of cells and for subsequent analysis by photoluminescence method. For the modification of glass/ZnO-NRs platforms $1.25 \mu \mathrm{g} / \mathrm{ml} ; 2.5 \mu \mathrm{g} / \mathrm{ml} ; 6.25 \mu \mathrm{g} / \mathrm{ml} ; 12.5 \mu \mathrm{g} / \mathrm{ml}$ and $25.0 \mu \mathrm{g} / \mathrm{ml}$ concentrations of monoclonal antibody were used.

Photoluminescence based evaluation reveals that anti-CD19FITC* modified glass/ZnO-NRs (glass/ZnO-NRs/anti-CD19-FITC*) leads to an increase in PL intensity and this increase of PL signal in the range of monoclonal antibody concentration from 1.25 till $6.25 \mu \mathrm{g} / \mathrm{ml}$ (Fig. 7). In a case of formation of glass/ZnO-NRs/anti-CD19-FITC* structure using $1.25 \mu \mathrm{g} / \mathrm{ml}$ of anti-CD19-FITC* solution the PL intensity of ZnO-NRs was about 15,500 a.u.; using $2.5 \mu \mathrm{g} / \mathrm{ml}-17,700$ a.u.; and using $6.25 \mu \mathrm{g} / \mathrm{ml}-21,500$ a.u., while in glass/ZnO-NRs/anti-CD19FITC* structures formed using 12.5 and $25.0 \mu \mathrm{g} / \mathrm{ml}$ of anti-CD19-FITC* were characterized by saturation of PL intensity due to saturation of adsorption sites on the surface of $\mathrm{ZnO}$ nanorods (Fig. 7). Hence, from here presented data we can conclude that $6.25 \mu \mathrm{g} / \mathrm{ml}$ is an optimal concentration of anti-CD19-FITC* for the design of glass/ZnO-NRs/antiCD19-FITC* structure, which was supposed to be sensitive to the B- 
(a)

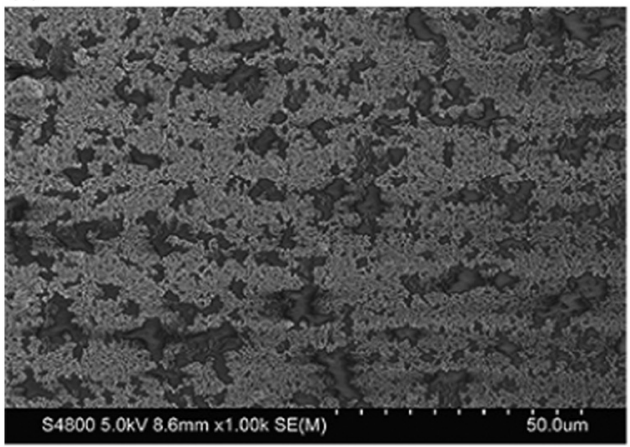

(c)

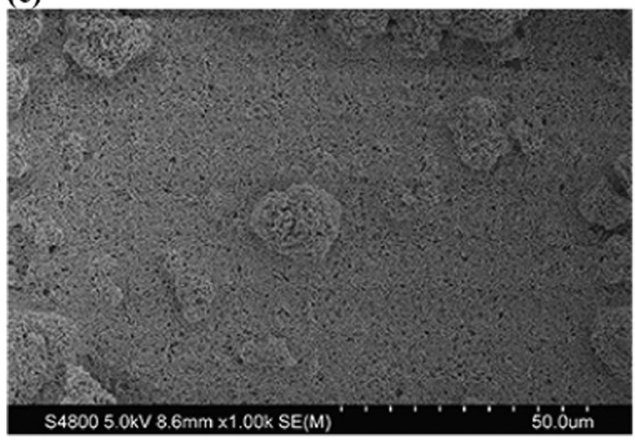

(b)

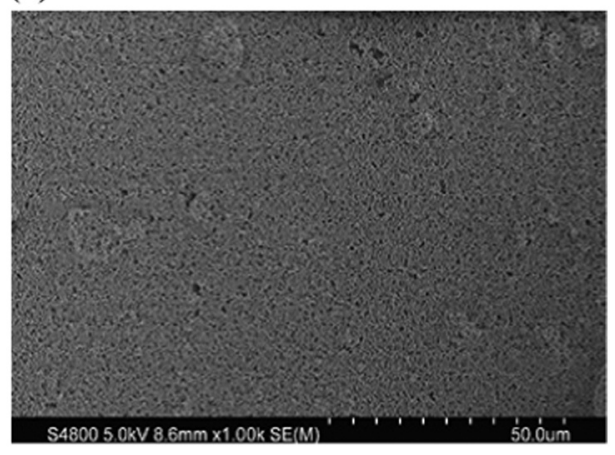

(d)

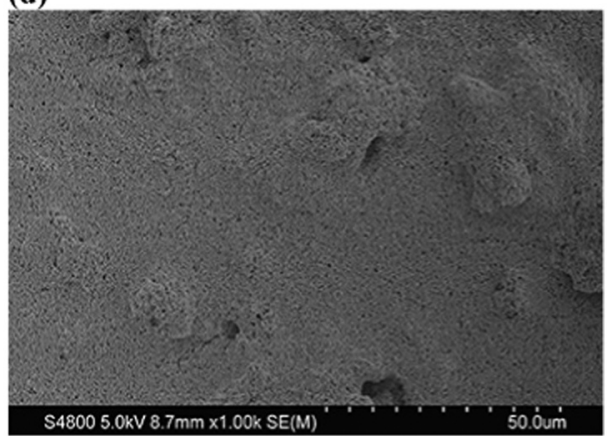

Fig. 4. SEM images of glass/ZnO-NRs modified by $1 \mathrm{mg} / \mathrm{ml}$ (a); $2.5 \mathrm{mg} / \mathrm{ml}$ (b); $5 \mathrm{mg} / \mathrm{ml}$ (c); $10 \mathrm{mg} / \mathrm{ml}$ (d) concentrations of ZnO-NRs after annealing at $300{ }^{\circ} \mathrm{C}$.
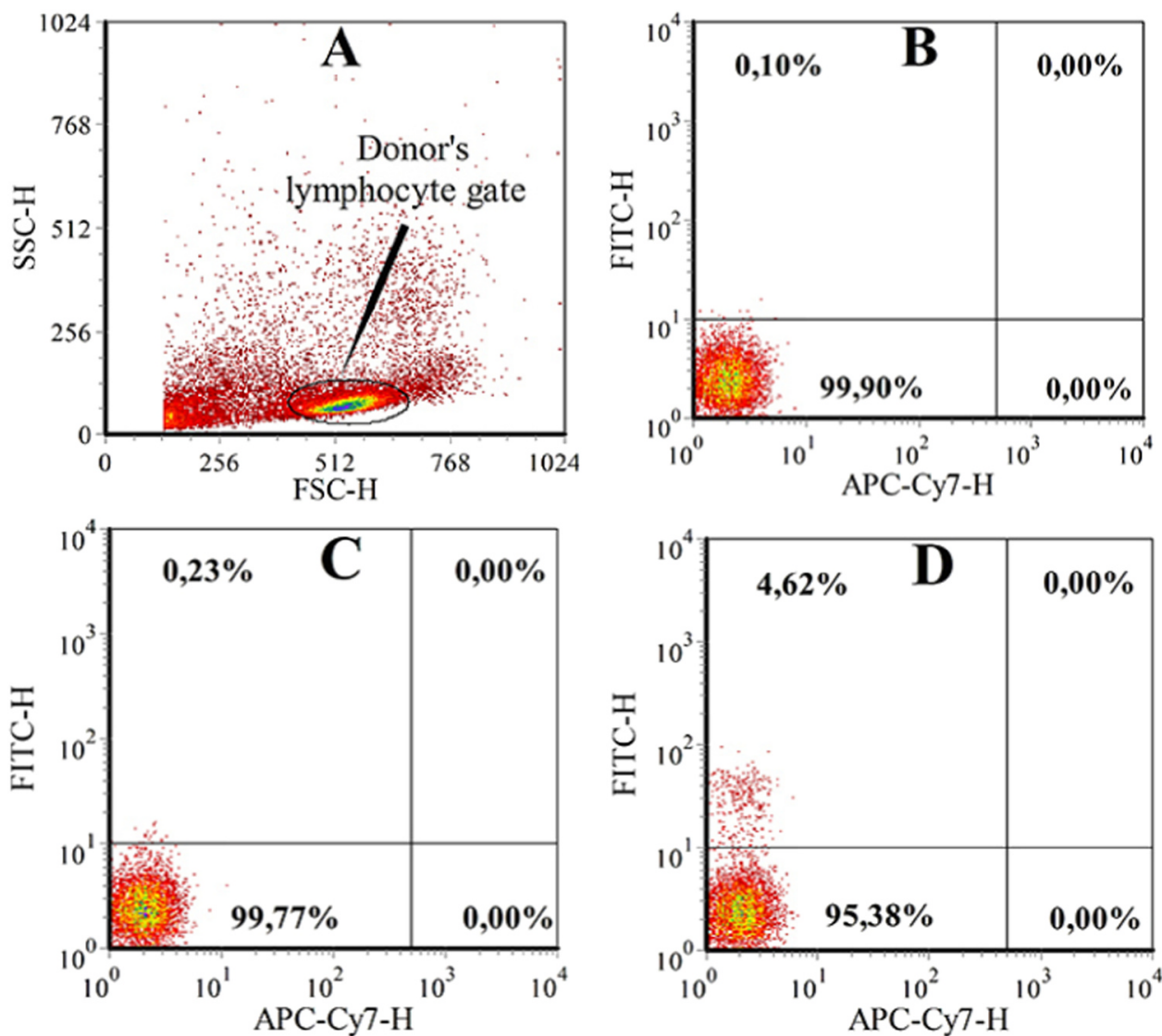

Fig. 5. Flow-cytometry based analysis of Blymphocytic antigen CD19 in human donor's lymphocytes where (A) Dot-plot analysis of PBMCs total population. Abscissa: forward scatter (cell size); ordinates: side scatter (cell density); (B, C, D) Flow-cytometry quadrant analysis of PBMCs: autofluorescence of cells (B), anti-IgG1-FITC* labeled cells (C), antiCD19-FITC* labeled cells. Upper left quadrant: IgG1- (C) or CD19-possitive cells (D). Numbering refers to the percentage of B-cells in PBMCs total population. 

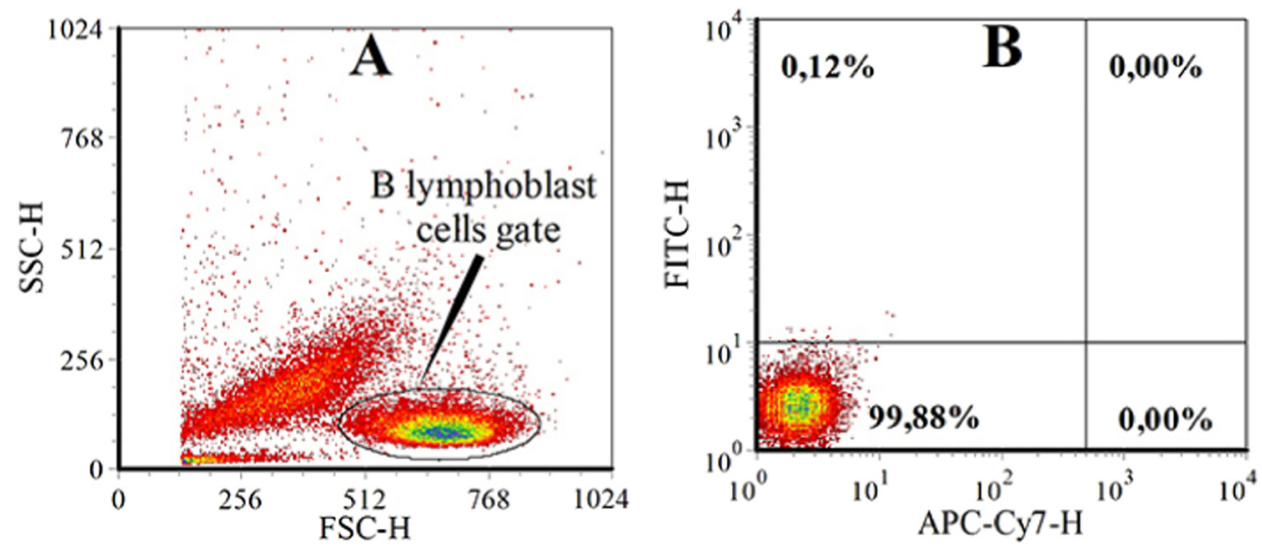

Fig. 6. Flow cytometry based analysis of Blymphocytic antigen CD19 in human B-lymphoblastoid cell line IM9 where: (A) Dot-plot analysis of IM9 cell line. Abscissa: forward scatter (cell size); ordinates: side scatter (cell density); (B, C, D) Flow cytometric quadrant analysis of IM9 cell line: autofluorescence of cells (B), anti-IgG1-FITC* labeled cells (C), anti-CD19-FITC* labeled cells. Upper left quadrant: IgG1- (C) or CD19-possitive cells (D). Numbering refers to the percentage of B-cells in IM9 cell line.
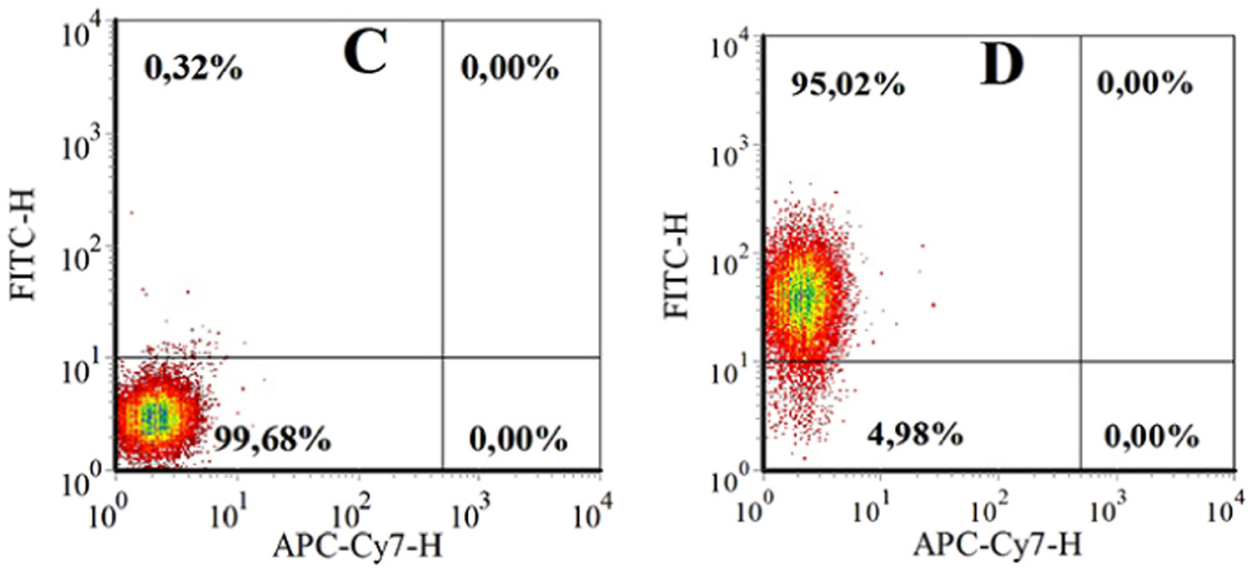

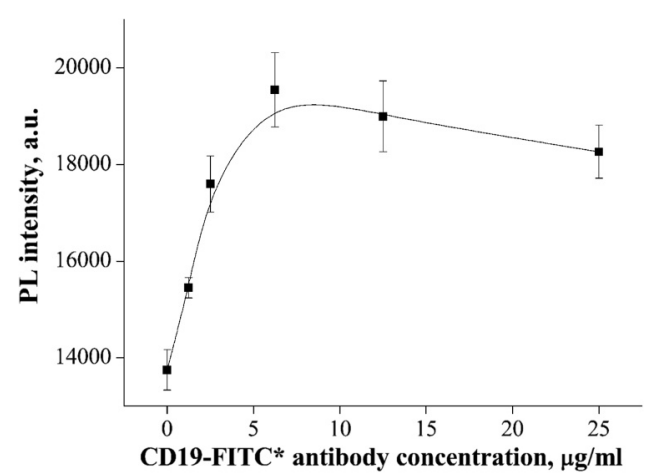

Fig. 7. Mean values of PL intensities of glass/ZnO-NRs/anti-CD19-FITC* structures formed from solution containing $1.25-25.0 \mu \mathrm{g} / \mathrm{ml}$ of anti-CD19FITC*.

lymphocytes, because this concentration of anti-CD19-FITC* provides the most efficient coverage of the ZnO-NRs.

The most plausible mechanism of anti-CD19-FITC* adsorption on $\mathrm{ZnO}-\mathrm{NRs}$ is based on electrostatic interaction between the surface charge of $\mathrm{ZnO}$ and the charge of proteins (in our case fluorescein-conjugated mouse anti-human CD19 monoclonal antibody) and van-derWaals interaction [6]. We suppose that the observed changes in $\mathrm{ZnO}$ NRs photoluminescence can be explained by non-covalent binding of ZnO-NRs with mouse anti-human CD19-FITC*.

The proteins are bound to $\mathrm{ZnO}$-NRs surface by several functional groups. In order to prove the formation of bonds between the $\mathrm{ZnO}-\mathrm{NRs}$, deposited on a glass substrate and monoclonal antibody - anti-CD19FITC*, the experiments with anti-CD19-FITC* fixation by the paraformaldehyde (PFA) that cross-link thiol ( $\mathrm{SH}-)$, amine $\left(\mathrm{NH}_{2}-\right)$, carboxyl ( $\mathrm{COOH}-)$, hydroxyl (OH-) groups of protein molecules were conducted. Anti-CD19-FITC* were pretreated with $1 \%$ paraformaldehyde solution

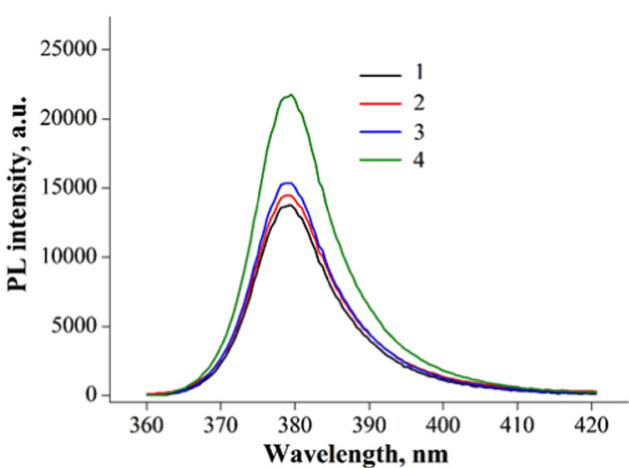

Fig. 8. PL spectra of glass/ZnO-NRs platform modified by anti-CD19FITC*(glass/ZnO-NRs/anti-CD19-FITC*): 1 - glass/ZnO-NRs, 2 - glass/ZnONRs/PFA, 3 - glass/ZnO-NRs/PFA/anti-CD19-FITC*, 4 - glass/ZnO-NRs/antiCD19-FITC*.

and dropped on a ZnO-NRs platform. Fig. 8 shows that the NBE emission of ZnO-NRs has increased after the immobilization of anti-CD19FITC* at a concentration of $6.75 \mu \mathrm{g} / \mathrm{ml}$. After the fixation of anti-CD19FITC* with PFA the reduction of PL intensity until values corresponding the ZnO-NRs with PBS and PFA was observed. Interestingly, that PL intensity of ZnO-NRs after the paraformaldehyde solution addition did not changed if compared to values corresponding to that observed for ZnO-NRs after addition of PBS (Fig. 8). These results support hypothesis that electron-rich groups, such as $\mathrm{SH}-, \mathrm{OH}-, \mathrm{NH}_{2}$, of the ligands (in our case ligand is anti-CD19-FITC*) improve the PL of ZnO-NRs. Previously, we have investigated non-specific interaction between surface of $\mathrm{ZnO}$ and biomolecules [15]. The non significant changes of $\mathrm{ZnO}$ emission were observed as result of interaction with non labeled antibodies. Because the FITC* absorption and emission ranges are out of excitation and emission of $\mathrm{ZnO}$ nanorods, the interaction between FITC* and $\mathrm{ZnO}$, 


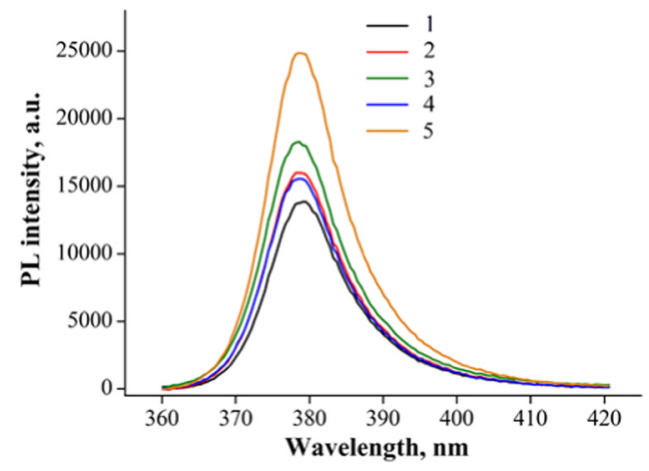

Fig. 9. PL spectra of bare ZnO-NRs, modified with cell lines: 1 - glass/ZnO-NRs, 2 - glass/ZnO-NRs/PBMC, 3 - glass/ZnO-NRs/PBMC/anti-CD19-FITC*, 4 glass/ZnO-NRs/IM9, 5 - glass/ZnO-NRs/IM9/anti-CD19-FITC*.

which was previously reported by Gupta et al. [28], plays the most important role for the increase of PL. Gupta et al. reported that integrated intensity of $\mathrm{ZnO}$ photoluminescence increases after the modification $\mathrm{ZnO}$ by FITC* [28]. According to Gupta et al., chemical binding between $\mathrm{ZnO}$ and FITC* is formed [28].

3.4. Microstructure and photoluminescence properties of $\mathrm{ZnO}-\mathrm{NRs}$ after the modification by cells conjugated with FITC* labeled monoclonal antibodies

Immunophenotyping of donor's peripheral mononuclear cells and human's B-lymphoblast cell line IM9 for the estimation of CD19 marker expression on cell surface revealed $4.62 \%$ and $95.02 \%$, respectively. To analyze the possibility of detection of B-lymphocytes using glass/ZnONR platforms the PL spectrum was recorded after the interaction of both cell lines (IM9+ anti-CD19-FITC* and PBMC+ anti-CD19-FITC*) conjugated with anti-CD19-FITC*.

Fig. 9 shows that NBE emission peak of glass/ZnO-NR platforms after the treatment by FITC* non-labeled by anti-CD19-FITC* cells: IM9 cell line and PBMC is diffrent from NBE emission peak, which is typical for ZnO-NRs after PBS addition in the range of $10-15 \%$. However after the immobilization of PBMC + anti-CD19-FITC* and IM9+ anti-CD19FITC* cells on the ZnO-NRs platform the PL intensity is increased from 13,700 a.u. (ZnO-NRs with PBS) till 18,300 and 25,000 a.u., respectively (Fig. 9).

Further, the sensitivity of the prepared ZnO-NRs-based platforms was studied in a wide range of B-lymphocytes concentrations (Figs. 10 and 11). For this B-lymphoblast cells pre-modified with anti-CD19FITC* and anti-IgG1-FITC* antibodies were detected by the intensity of NBE spectra at different concentrations ranging from 10 till 1000 cells per $1 \mathrm{~mm}^{2}$ on the surface of glass/ZnO-NRs platform. Fig. 10A shows that PL intensity of ZnO-NRs increased by the rise of CD19-positive cell (or B-lymphocyte) in the investigated sample. However at high IM9 cell concentrations (500-1000 cells per $1 \mathrm{~mm}^{2}$ ) the intensity of PL spectra reached steady-state value. The similar tendency of PL intensity increase we have registered after the interaction of cells labeled with antiIgG1-FITC* with ZnO-NRs surface (Fig. 10B) that characterizes the nonspecific background signal caused by the anti-CD19-FITC*.

In the Fig. 11 we represent dynamic changes of $\mathrm{ZnO}$-NRs photoluminescence after the incubation of human B-lymphoblast cell line IM9 pre-modified with anti-CD19-FITC* and anti-IgG1-FITC* on the surface of ZnO-NRs. These results were observed after the subtraction of PL intensity values of glass/ZnO-NRs structure from values of PL intensity of glass/ZnO-NRs/IM9+ anti-CD19-FITC* and glass/ZnO-NRs/ IM9 + anti-IgG1-FITC*, respectively. This approach provides the opportunity to register the effect, caused by the interaction of the B-cells labeled with anti-CD19-FITC* and anti-IgG1-FITC* under the adhesion to ZnO-NRs based platforms. The values of ZnO-NRs PL intensity after immobilization of cells conjugated with anti-IgG1-FITC* are used as an
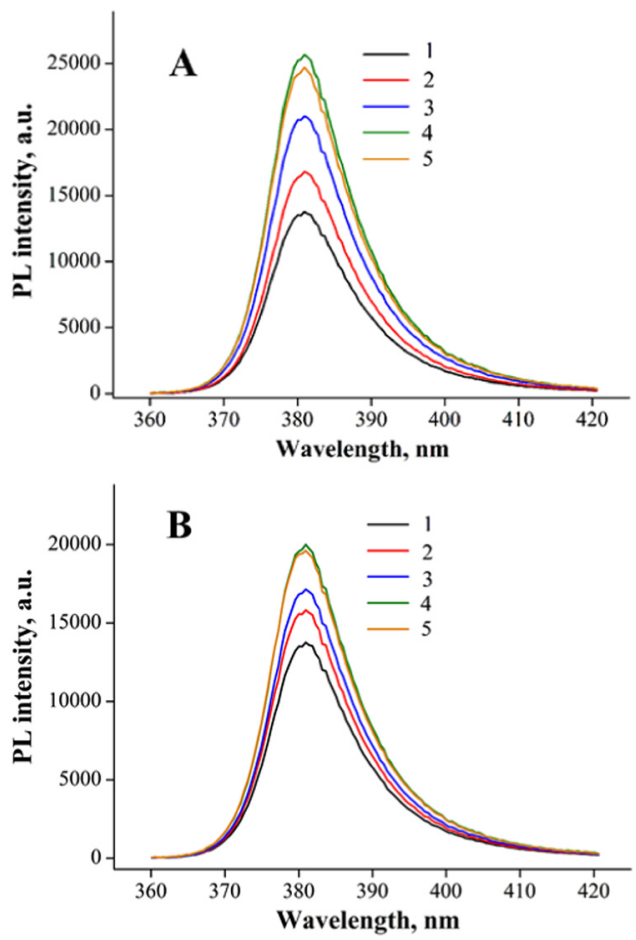

Fig. 10. PL spectra of: A) - glass/ZnO-NRs/IM9/anti-CD19-FITC*(1-0 cells, 2-10 cells, 3-100 cells, 4-500 cells, 5-1000 cells); B) - glass/ZnO-NRs/IM9/ anti- IgG1-FITC*(1-0 cells, 2-10 cells, 3-100 cells, 4-500 cells, 5-1000 cells).

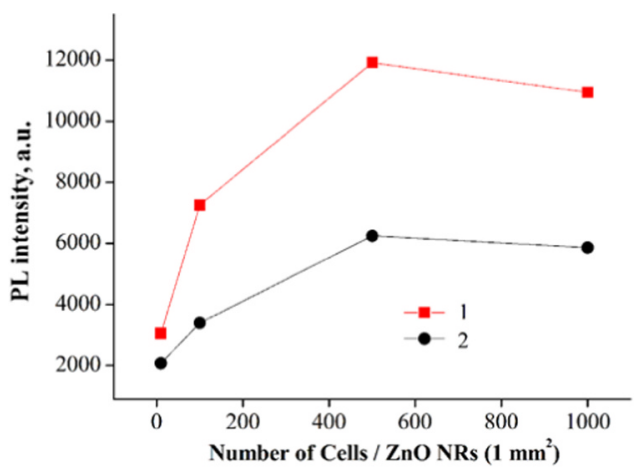

Fig. 11. PL intensity ZnO-NRs vs cells concentration: 1 - glass/ZnO-NRs/IM9/ anti-CD19-FITC*, 2 - glass/ZnO-NRs/IM9/anti-IgG1-FITC*.

initial point for calculation of the net effect in glass/ZnO-NR platform response. Hence, from Fig. 11 we can conclude that net effect was averaged from $50 \%$ (10 cells per $1 \mathrm{~mm}^{2}$ ) until $200 \%$ (500 cells per $1 \mathrm{~mm}^{2}$ ).

Using scanning electron microscopy images of IM9 cell line conjugated in vitro with anti-CD19-FITC* monoclonal antibody (IM9+ antiCD19-FITC*) (Fig. 12A and B) and with anti-IgG1-FITC* polyclonal antibody (IM9 + anti-IgG1-FITC*) in order to perform isotype control (Fig. 13A and B) after the adhesion on the glass/ZnO-NRs were obtained. It is shown that the anti-CD19-FITC* monoclonal antibody (Fig. 12B) and anti-IgG1-FITC* used for isotype control (Fig. 13B) are localized on the IM9 cell line surface as globules that results in the increase of the surface area of IM9 cell line and area for the adhesion of cells with ZnO-NRs-based platforms. Thus, we can conclude that the obtained rise of PL intensity of ZnO-NRs (NBE peak) after the immobilization of FITC*-labeled antibodies and cells (Figs. 7, 9, 10) is a result of the decrease of negative surface potential [29] and an increase in Zn-S bond formation on ZnO-NRs-based platforms [30]. 
(A)

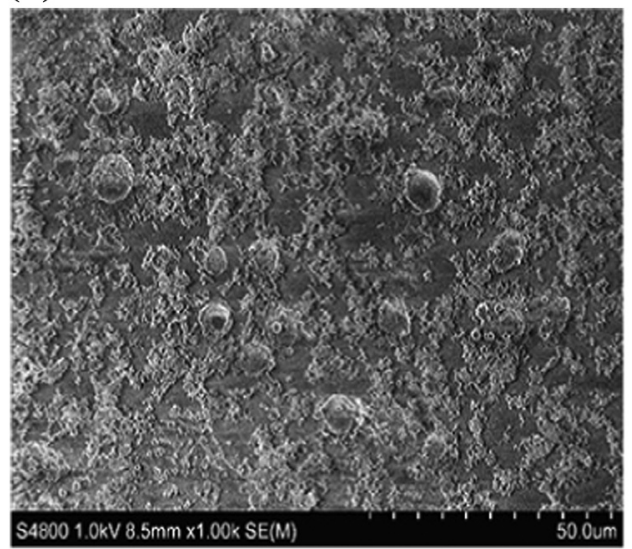

(B)

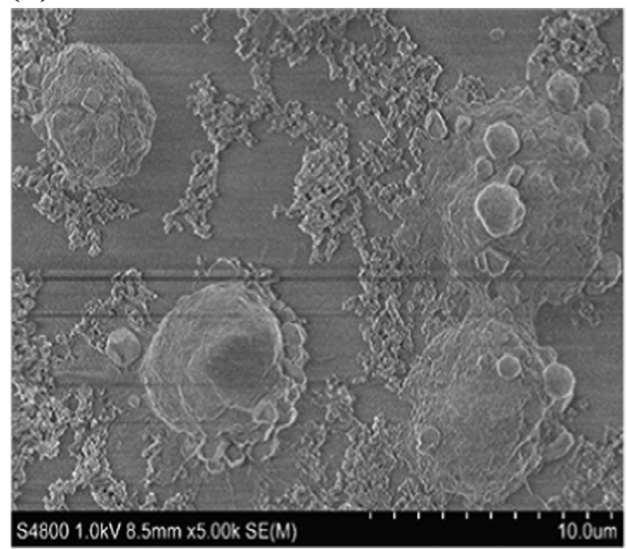

Fig. 12. SEM images of IM9 cell line conjugated with anti-CD19-FITC*(IM9+ anti-CD19-FITC*) immobilized on the surface of glass/ZnO-NRs structure at 1.00k (A) and 5.00k (B) magnifications.

(A)

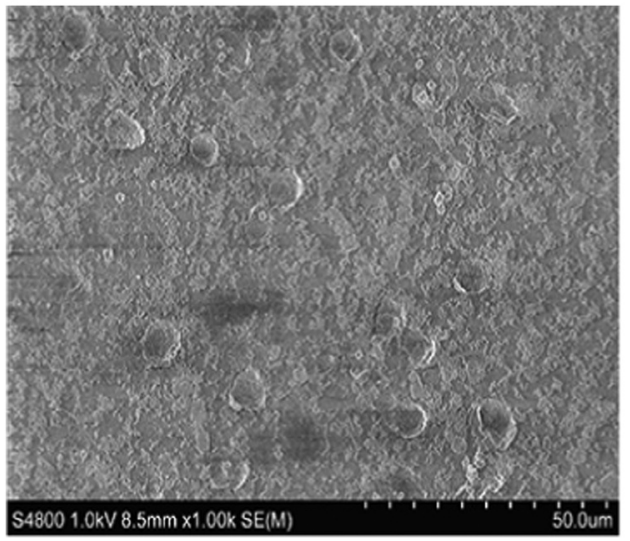

(B)

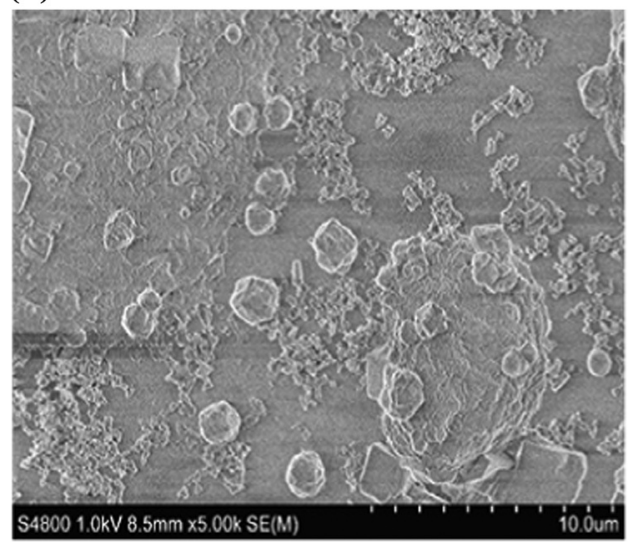

Fig. 13. SEM images IM9 cell line conjugated with anti-IgG1-FITC*(IM9+ anti-IgG1-FITC*) immobilized on glass/ZnO-NRs at 1.00k (A) and 5.00k (B) magnifications.

\subsection{Raman spectroscopy evaluation of glass/ZnO-NRs-based} immunosensing platform before and after the interaction with target cells

Raman scattering was applied to study the chemical bonds that arise during the immobilization of anti-CD19-FITC* antibodies on the surface of glass/ZnO-NRs and after interaction with cells. Raman spectra were registered for unmodified glass/ZnO-NRs, glass/ZnO-NRs modified by anti-CD19-FITC* (glass/ZnO-NRs/anti-CD19-FITC*) structures and for IM9 cell line conjugated in vitro with anti-CD19-FITC* and immobilized on glass/ZnO-NRs platform (glass/ZnO-NRs/IM9 + anti-CD19-FITC*).

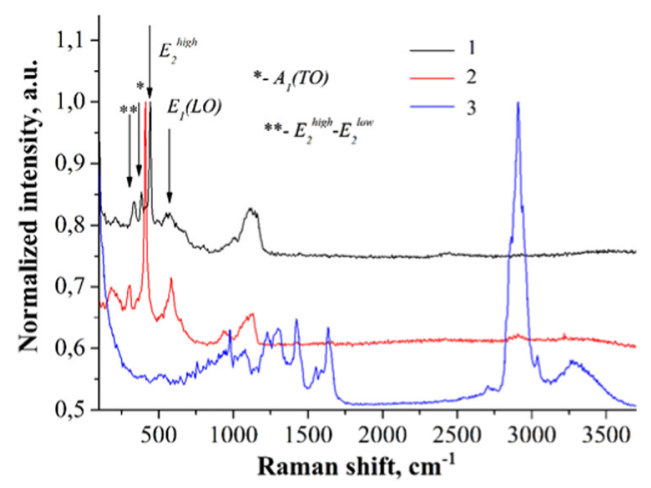

Fig. 14. Raman spectra ZnO-NRs after modification: 1 - glass/ZnO-NRs/, 2 glass/ZnO-NRs/anti-CD19-FITC*, 3 - glass/ZnO-NRs/IM9/anti-CD19-FITC*.
Raman spectra of ZnO-NRs before and after the functionalization are shown in Fig. 14. According to [31], Raman peaks of ZnO-NRs, located at $326,382,442$ and $574 \mathrm{~cm}^{-1}$ correspond to $\mathrm{E}_{2}$ high $-\mathrm{E}_{2}{ }^{\text {low }}, \mathrm{A}_{1}(\mathrm{LO}), \mathrm{E}_{2}$ high and $\mathrm{E}_{1}(\mathrm{LO})$, respectively. Immobilization of anti-CD19-FITC* on ZnONRs surface resulted in $30 \mathrm{~cm}^{-1}$ shift of the peaks at 326 and $442 \mathrm{~cm}^{-1}$ towards lower wave numbers, peak at $382 \mathrm{~cm}^{-1}$ has been quenched, peak at $574 \mathrm{~cm}^{-1}$ has shifted to $582 \mathrm{~cm}^{-1}$. ZnO-NRs treated by complex IM9 cells with anti-CD19-FITC* resulted to complete the quenching of Raman peaks attributed to ZnO-NRs. New peaks, in the range of $1250-1750 \mathrm{~cm}^{-1}$ and $2950-3500 \mathrm{~cm}^{-1}$ have been observed, which corresponds to vibrations of amino and carboxyle groups [32,33].

\section{Conclusion}

This study the applicability of ZnO-nanorod-based immunosensing platform for the detection cancer cell (B-lymphoblastoid cell line IM9) has been demonstrated. The photoluminescent spectra of zinc oxide nanorods exhibit strong near-band-edge (NBE) emission, we have applied this part of PL spectra for the evaluation of glass/ZnO-NR-based platforms before and after the immobilization of antibodies and interaction with human blood cells.

SEM and PL based investigations revealed that $6,25 \mu \mathrm{g} / \mathrm{ml}$ is an optimal concentration of anti-CD19-FITC* for the modification of glass/ ZnO-NRs-based substrate in order to design immunosensor. Moreover we observed that electron-rich groups, such as $\mathrm{SH}-, \mathrm{OH}-, \mathrm{NH}_{2^{-}}$and FITC* of anti-CD19-FITC* monoclonal antibody increase the PL of ZnONRs. 
Using flow cytometry we have demonstrated that positive expression rates of CD19 marker in human B-lymphoblastoid cell line IM9 is on the average $95 \%$ compared with that of donor's lymphocytes where only $5 \%$ of CD19 positive cells were detected. Meanwhile it was shown that B-lymphoblastoid cells modified with anti-CD19-FITC* bind to ZnO-NR platforms with high selectivity. It was shown that PL signal of glass/ZnO-NRs/IM9 + anti-CD19-FITC* platform increases by $50-70 \%$ in comparison with the signal which is registered for glass/ZnO-NRs/ PBMC+ anti-CD19-FITC* structure. The rise of the ZnO-NRs photoluminescence intensity has correlated with CD19 positive cells number in the investigated populations.

Simultaneously, using SEM and Raman spectroscopy the structural and electronic properties of formed glass/ZnO-NRs platforms after the immobilization of B-lymphoblasts labeled with anti-CD19-FITC* and anti-IgG1-FITC* were investigated. Raman spectroscopy data revealed that Raman signal is changing after the immobilization of anti-CD19FITC* on the ZnO-NRs-based platforms and their interaction with target cells.

The PL measurements confirmed that the photoluminescence of ZnO-NRs is useful for the design of devoted immunosensors for the determination of human B-lymphoblasts at low cell concentrations from 10 until 500 cells/(per $1 \mathrm{~mm}^{2}$ of ZnO-NRs-based platform).

\section{Acknowledgments}

This research has received funding from the European Union's Horizon 2020 research and innovation programme under grant agreement no. 778157 CanBioSe (2018-2021), Ukraine-Latvia joint project 'FP-20322-ZF-N-840 "Algoritma optimizēěana audzēju progresēšanas un ārstēšanas efektivitātes biokīmisko raksturlielumu noteikšanai ar biosensoriem". The authors thank Prof. A.I. Svirnovski and Dr. V.V. Pasiukov (Minsk, Belarus) for giving human B-lymphoblastoid cell line IM9 for current investigation.

\section{References}

[1] N. Chiorazzi, R.R. Kanti, M. Ferrarini, Mechanisms of disease Chronic Lymphocytic Leukemia, N. Engl. J. Med. 352 (2005) 804-815, https://doi.org/10.1056/ NEJMra041720.

[2] J. Chen, N.A.J. McMillan, Molecular basis of pathogenesis, prognosis and therapy in chronic lymphocytic leukaemia, Cancer Biol. Ther. 7 (2008) 174-179, https://doi. org/10.4161/cbt.7.2.5262.

[3] R.L. Siegel, K.D. Miller, A. Jemal, R.L. Cancer Siegel, K.D. Miller, A. Jemal, Cancer statistics, 2016, CA Cancer J. Clin. 66 (1) (2016) 7-30, https://doi.org/10.3322/ caac. $21332\langle$ https://doi.org/10.3322/caac.21332tatistics〉.

[4] A.I. Svirnovski, T.V. Shman, T.F. Serhiyenka, V.P. Savitski, V.V. Smolnikova, U.U. Fedasenka, ABCB1 and ABCG2 proteins, their functional activity and gene expression in concert with drug sensitivity of leukemia cells, Hematology 14 (2009) 204-212, https://doi.org/10.1179/102453309X426218.

[5] A.C. Rawstron, F.L. Bennett, S.J.M. O'Connor, M. Kwok, J.A.L. Fenton, M. Plummer, R. de Tute, R.G. Owen, S.J. Richards, A.S. Jack, P. Hillmen, Monoclonal B-cell lymphocytosis and chronic lymphocytic leukemia, N. Engl. J. Med. 359 (2008) 575-583, https://doi.org/10.1056/NEJMoa075290.

[6] A. Tereshchenko, M. Bechelany, R. Viter, V. Khranovskyy, V. Smyntyna, N. Starodub, R. Yakimova, Optical biosensors based on ZnO nanostructures: advantages and perspectives: a review, Sens. Actuators B Chem. 229 (2016) 664-677, https://doi.org/10.1016/j.snb.2016.01.099.

[7] R. Viter, N. Starodub, V. Smyntyna, A. Tereschenko, A. Kusevitch, J. Sitnik, J. Buk, J. Macakd, Immune biosensor based on silica nanotube hydrogels for rapid biochemical diagnostics of bovine retroviral Leukemia, Procedia Eng. (2011) 948-951, https://doi.org/10.1016/j.proeng.2011.12.233.

[8] R. Viter, V. Smyntyna, N. Starodub, a. Tereshchenko, a. Kusevitch, I. Doychoa, S. Geveluk, N. Slishik, J. Buk, J. Duchoslav, J. Lubchuk, I. Konup, a. Ubelis, J. Spigulis, Novel immune TiO2 photoluminescence biosensors for leucosis detection, Procedia Eng. 47 (2012) 338-341, https://doi.org/10.1016/j.proeng.2012.09. 152.

[9] Y. Huang, Q. Wen, J.H. Jiang, G.L. Shen, R.Q. Yu, A novel electrochemical immunosensor based on hydrogen evolution inhibition by enzymatic copper deposition on platinum nanoparticle-modified electrode, Biosens. Bioelectron. 24 (2008) 600-605, https://doi.org/10.1016/j.bios.2008.06.002.

[10] J.-I. Hahm, Zinc oxide nanomaterials for biomedical fluorescence detection, J.
Nanosci. Nanotechnol. 14 (2014) 475-486, https://doi.org/10.1166/jnn.2014 9099.

[11] O. Graniel, M. Weber, S. Balme, P. Miele, M. Bechelany, Atomic layer deposition for biosensing applications, Biosens. Bioelectron. 122 (2018) 147-159, https://doi. org/10.1016/j.bios.2018.09.038.

[12] A. Tereshchenko, V. Fedorenko, V. Smyntyna, I. Konup, A. Konup, M. Eriksson, R. Yakimova, A. Ramanavicius, S. Balme, M. Bechelany, ZnO films formed by atomic layer deposition as an optical biosensor platform for the detection of Grapevine virus A-type proteins, Biosens. Bioelectron. 92 (2017) 763-769, https:// doi.org/10.1016/J.BIOS.2016.09.071.

[13] C.D. Corso, A. Dickherber, W.D. Hunt, An investigation of antibody immobilization methods employing organosilanes on planar $\mathrm{ZnO}$ surfaces for biosensor applications, Biosens. Bioelectron. 24 (2008) 805-811, https://doi.org/10.1016/j.bios. 2008.07.011.

[14] B. Gu, C. Xu, C. Yang, S. Liu, M. Wang, ZnO quantum dot labeled immunosensor for carbohydrate antigen 19-9, Biosens. Bioelectron. 26 (2011) 2720-2723, https:// doi.org/10.1016/j.bios.2010.09.031.

[15] R. Viter, V. Khranovskyy, N. Starodub, Application of room temperature photoluminescence from ZnO nano-rods for Salmonella detection, IEEE Sens. J. 14 (2014) 2028-2034〈http://ieeexplore.ieee.org/xpls/abs all.jsp?arnumber $=6750731\rangle$ (Accessed 16 September 2014).

[16] R. Viter, M. Savchuk, I. Iatsunskyi, Z. Pietralik, N. Starodub, N. Shpyrka, A. Ramanaviciene, A. Ramanavicius, Analytical, thermodynamical and kinetic characteristics of photoluminescence immunosensor for the determination of Ochratoxin A, Biosens. Bioelectron. 99 (2018) 237-243, https://doi.org/10.1016/j. bios.2017.07.056.

[17] R. Viter, K. Jekabsons, Z. Kalnina, N. Poletaev, S.H. Hsu, U. Riekstina, Bioanalytical system for detection of cancer cells with photoluminescent $\mathrm{ZnO}$ nanorods, Nanotechnology 27 (2016) 465101, https://doi.org/10.1088/0957-4484/27/46/ 465101.

[18] A.N. Zolotko, N.I. Poletaev, Y.I. Vovchuk, Gas-disperse synthesis of metal oxide particles, Combust. Explos. Shock Waves 51 (2015), https://doi.org/10.1134/ S0010508215020094.

[19] R. Viter, K. Jekabsons, Z. Kalnina, N. Poletaev, S.H. Hsu, U. Riekstina, Bioanalytical system for detection of cancer cells with photoluminescent $\mathrm{ZnO}$ nanorods, Nanotechnology 27 (2016) 465101, https://doi.org/10.1088/0957-4484/27/46/ 465101.

[20] R. Viter, A. Tereshchenko, V. Smyntyna, J. Ogorodniichuk, N. Starodub, R. Yakimova, V. Khranovskyy, A. Ramanavicius, Toward development of optical biosensors based on photoluminescence of $\mathrm{TiO}_{2}$ nanoparticles for the detection of Salmonella, Sensors Actuators B Chem. 252 (2017) 95-102, https://doi.org/10. 1016/j.snb.2017.05.139.

[21] M. Willander, S. Al-Hilli, ZnO nanorods as an intracellular sensor for $\mathrm{pH}$ measurements, Methods Mol. Biol. 544 (2009) 187-200, https://doi.org/10.1007/978 1-59745-483-4_13.

[22] B.S. Kang, F. Ren, Y.W. Heo, L.C. Tien, D.P. Norton, S.J. Pearton, pH measurements with single $\mathrm{ZnO}$ nanorods integrated with a microchannel, Appl. Phys. Lett. 86 (2005) 1-3, https://doi.org/10.1063/1.1883330.

[23] N. Kumar, A. Dorfman, J.I. Hahm, Ultrasensitive DNA sequence detection using nanoscale ZnO sensor arrays, Nanotechnology 17 (2006) 2875-2881, https://doi. org /10.1088/0957-4484/17/12/009.

[24] A. Dorfman, N. Kumar, J.I. Hahm, Highly sensitive biomolecular fluorescence detection using nanoscale ZnO platforms, Langmuir 22 (2006) 4890-4895, https:// doi.org/10.1021/la053270.

[25] A. Dorfman, O. Parajuli, N. Kumar, J.-I. Hahm, Novel telomeric repeat elongation assay performed on zinc oxide nanorod array supports, J. Nanosci. Nanotechnol. 8 (2008) 410-415, https://doi.org/10.1166/jnn.2008.146.

[26] Z.M. Liao, H.Z. Zhang, Y.B. Zhou, J. Xu, J.M. Zhang, D.P. Yu, Surface effects on photoluminescence of single $\mathrm{ZnO}$ nanowires, Phys. Lett. Sect. A Gen. At. Solid State Phys. 372 (2008) 4505-4509, https://doi.org/10.1016/j.physleta.2008.04.013.

[27] X.T. Zhang, Y.C. Liu, Z.Z. Zhi, J.Y. Zhang, Y.M. Lu, D.Z. Shen, W. Xu, X.W. Fan, X.G. Kong, Temperature dependence of excitonic luminescence from nanocrystalline ZnO films, J. Lumin. 99 (2002) 149-154, https://doi.org/10.1016/S00222313(02)00331-9.

[28] J. Gupta, P. Bhargava, D. Bahadur, Fluorescent $\mathrm{ZnO}$ for imaging and induction of DNA fragmentation and ROS-mediated apoptosis in cancer cells, J. Mater. Chem. B. 3 (2015) 1968-1978, https://doi.org/10.1039/c4tb01661k.

[29] J. Chen, R.E. Ruther, Y. Tan, L.M. Bishop, R.J. Hamers, Molecular adsorption on $\mathrm{ZnO}(10 \overline{10})$ single-crystal surfaces: morphology and charge transfer, Langmuir 28 (2012) 10437-10445, https://doi.org/10.1021/la301347t.

[30] J. Singh, J. Im, E.J. Watters, J.E. Whitten, J.W. Soares, D.M. Steeves, Thiol dosing of $\mathrm{ZnO}$ single crystals and nanorods: surface chemistry and photoluminescence, Surf. Sci. 609 (2013) 183-189, https://doi.org/10.1016/j.susc.2012.12.006.

[31] I. Mihailova, V. Gerbreders, E. Tamanis, E. Sledevskis, R. Viter, P. Sarajevs, Synthesis of $\mathrm{ZnO}$ nanoneedles by thermal oxidation of $\mathrm{Zn}$ thin films, J. Non Cryst. Solids 377 (2013) 212-216, https://doi.org/10.1016/j.jnoncrysol.2013.05.003.

[32] L. Mikoliunaite, R.D. Rodriguez, E. Sheremet, V. Kolchuzhin, J. Mehner, A. Ramanavicius, D.R.T. Zahn, The substrate matters in the Raman spectroscopy analysis of cells, Sci. Rep. 5 (2015), https://doi.org/10.1038/srep13150.

[33] P. Rösch, M. Harz, K.D. Peschke, O. Ronneberger, H. Burkhardt, J. Popp, Identification of single eukaryotic cells with micro-Raman spectroscopy, Biopolymers 82 (2006) 312-316, https://doi.org/10.1002/bip.20449. 